\title{
Response by vessel operators to protection measures for right whales Eubalaena glacialis in the southeast US calving ground
}

\author{
Kerry M. Lagueux*, Monica A. Zani, Amy R. Knowlton, Scott D. Kraus
}

New England Aquarium, Central Wharf, Boston, Massachusetts 02110, USA

\begin{abstract}
Vessel strikes are the leading cause of mortality for the endangered North Atlantic right whale Eubalaena glacialis. Prior to a December 2008 implementation of a mandatory, seasonally based vessel-speed rule (10 knots, $\left.18.5 \mathrm{~km} \mathrm{~h}^{-1}\right)$ along the eastern US seaboard, voluntary recommended speeds and routes were established. We used Automatic Identification System (AIS) data to evaluate and compare the compliance rates between the mandatory and voluntary measures to protect right whales in the southeast US critical habitat area off Florida and Georgia during the winters from 2005-06 to 2008-09. Vessel compliance was significantly higher under mandatory versus voluntary recommended speed restrictions, with compliance rates of 75 and $16 \%$, respectively. Average vessel speeds were slower under mandatory speed restrictions $\left(10.5 \mathrm{knots}, 19.6 \mathrm{~km} \mathrm{~h}^{-1}\right)$ compared to voluntary recommended speed restrictions $\left(14.5\right.$ knots, $\left.26.9 \mathrm{~km} \mathrm{~h}^{-1}\right)$. Although vessels only slow down when mandated, they change their routing voluntarily. Compliance rates with voluntary recommended routes steadily increased during this period, from $43 \%$ prior to rulemaking, to $52 \%$ during the first year, $84 \%$ in the second year, and $96 \%$ in the final year of the study. Combining reduced speeds with recommended routes reduces the probability of right whale mortality from ships by $71.9 \%$ from the pre-implementation period. These results support long-term implementation of both vessel-speed reduction and restricted vessel routes for the survival and recovery of the North Atlantic right whale.
\end{abstract}

KEY WORDS: Automatic Identification System $\cdot$ Right whale $\cdot$ Eubalaena glacialis $\cdot$ Speed restrictions $\cdot$ Recommended routes $\cdot$ Ship strike $\cdot$ Southeast USA

\section{INTRODUCTION}

The North Atlantic right whale Eubalaena glacialis population numbers $<500$ animals (North Atlantic Right Whale Consortium Report Card 2010, available at www.rightwhaleweb.org), despite international protection since 1935 and US federal protection since 1972. The coastal waters of the southeast US (SEUS) supports the only known calving ground for this right whale population (Kraus et al. 1986), with whales giving birth between December and March (Kraus \& Rolland 2007). Human sources of mortality, primarily from shipping and fishing, are known to be limiting the recovery in this species (Kraus 1990, Knowlton \& Kraus 2001, Kraus et al. 2005, Kraus \& Rolland 2007).
Right whale population models suggest that this species is declining because of human-caused mortalities; however, reducing the number of mortalities each year by only 2 female right whales can increase the growth rate to a recovery level (Fujiwara \& Caswell 2001). With vessel strikes as the leading cause of mortalities in right whales (Moore et al. 2007), the recovery of this species is highly dependent on reducing the number of lethal injuries from vessels. Lethal injuries to right whales caused from vessel strikes are dependent on the co-occurrence of whales and vessels as well as the size and speed of those vessels during impact (Laist et al. 2001, Vanderlaan et al. 2008). Most lethal ship strikes occurred from vessels that traveled at speeds $>14$ knots $\left(>25.9 \mathrm{~km} \mathrm{~h}^{-1}\right)$ and vessels $>80 \mathrm{~m}$ 
in length (Laist et al. 2001), with probabilities of a mortality event increasing from $20 \%$ at 8.6 knots $(15.9 \mathrm{~km}$ $\left.\mathrm{h}^{-1}\right)$ to $80 \%$ at $15 \mathrm{knots}\left(27.8 \mathrm{~km} \mathrm{~h}^{-1}\right.$; Vanderlaan \& Taggart 2007). Vessels traveling in the SEUS from 1999 to 2002 averaged 15 knots $\left(27.8 \mathrm{~km} \mathrm{~h}^{-1}\right.$; Ward-Geiger et al. 2005), so if a vessel strike occurred, the whale would most likely die from the encounter. In the SEUS right whale calving area there are 3 shipping channels that serve 2 naval bases and 3 commercial ports, including the port of Jacksonville, FL, one of the busiest in the USA. Of the 3 US critical habitat areas for this species, right whales are most at risk in the calving ground (Vanderlaan et al. 2009).

Aerial surveys for ship-strike mitigation have been flown in the SEUS since 1988 in an attempt to curb vessel strikes by informing vessel operators of near-realtime right whale sightings during the months of calving. Messaging to vessels was improved in 1999 with the implementation of the Mandatory Ship Reporting (MSR) system, which required all vessels of $\geq 300$ gross tons entering either of 2 MSR areas, one off the New England coast (encompassing 2 critical habitat areas: Cape Cod Bay and the Great South Channel) and one off the SEUS (encompassing the third critical habitat area: the southern calving ground), to report to a central server that sent an automated response to the vessel operator of the most recent sightings and navigational cautions and requirements around right whales (Ward-Geiger et al. 2005).

Despite the aerial surveys and the MSR system, right whales continued to be killed by vessel strikes. Beginning in 2004, NOAA proposed and implemented rules aimed at reducing vessel strikes by re-routing and slowing vessels when right whales are present off the east coast of the USA (NOAA 2004, 2006, 2008). After NOAA announced the ship strike reduction strategy in 2004, NOAA implemented recommended voluntary slow speeds of 12 knots $\left(22.2 \mathrm{~km} \mathrm{~h}^{-1}\right)$ in the calving ground. In the subsequent year, NOAA decreased the recommended speed to 10 knots $\left(18.5 \mathrm{~km} \mathrm{~h}^{-1}\right)$. The final speed rule was implemented on December 9, 2008, making it mandatory, not voluntary, for all vessels of length $\geq 65 \mathrm{ft}$ $(\geq 19.8 \mathrm{~m})$ to slow to $\leq 10$ knots $\left(\leq 18.5 \mathrm{~km} \mathrm{~h}^{-1}\right)$ in designated right whale management areas called Seasonal Management Areas (SMA), which follows the MSR boundary in the SEUS but extends 15 nautical miles (nmi) $(27.8 \mathrm{~km})$ further to the south (Fig. 1), but does not have automatic messaging to the vessels as the MSR area. In addition, NOAA added recommended routes to the nautical charts for the SEUS in November 2006, with the goal of minimizing transit time for vessels within the critical habitat area and routing vessels to areas with fewer right whales (USCG 2006).

The present study details the response of commercial vessels to operational measures to reduce ship

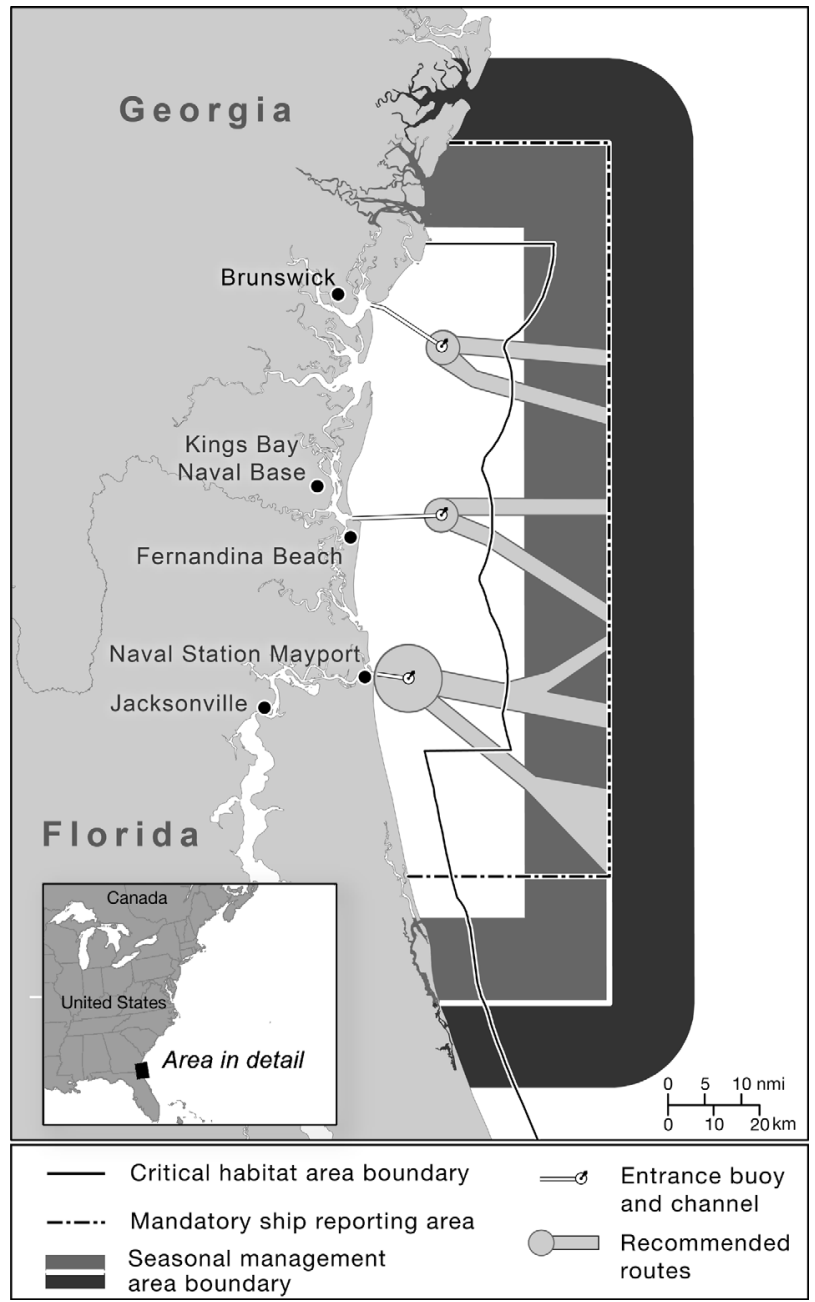

Fig. 1. Eubalaena glacialis. Southeast USA right whale habitat area, highlighting the critical habitat area, mandatory ship reporting area (MSR), and seasonal management area (SMA) offshore of Georgia and Florida, including the major ports, recommended routes, and areas used to summarize the average speed of vessels offshore (dark gray area) and inshore (medium gray area) of the MSR and SMA boundary

strikes of right whales in the SEUS habitat area. Specifically, we examined vessel compliance to speed and routing measures across years, and compared the effectiveness of recommended (voluntary) versus mandatory rules. Finally, we estimated the effectiveness of current rules on reducing mortality rates in right whales.

\section{MATERIALS AND METHODS}

Aerial surveys. The New England Aquarium (NEAq) conducted systematic surveys on days suitable for aerial surveys for right whales (winds $<17$ knots $[<31.2 \mathrm{~km}$ 
$\mathrm{h}^{-1}$ ], visibility $>2 \mathrm{nmi}[>3.7 \mathrm{~km}]$, covering approximately half of the MSR area between December 1 and March 31, from December 2005 through March 2009 (Fig. 1). Transects were flown in a Cessna 337 Skymaster at an altitude of 1000 feet (305 m) during daytime hours. The winter calving seasons will subsequently be referred to as Year 1 (2005-06), Year 2 (2006-07), Year 3 (2007-08), and Year 4 (2008-09). The management area is hereafter defined as either the MSR or the SMA depending on the year (MSR in Years 1 to 3; SMA in Year 4; Fig. 1). Surveys in Year 1 corresponded with recommended speeds of 12 knots $\left(22.2 \mathrm{~km} \mathrm{~h}^{-1}\right)$ for vessels in the management area with no recommended routes for vessels transiting in the area; Years 2 and 3 corresponded with recommended speeds of 10 knots $\left(18.5 \mathrm{~km} \mathrm{~h}^{-1}\right)$ and recommended routes; Year 4 corresponded with the new mandatory ship speed limit of 10 knots $\left(18.5 \mathrm{~km} \mathrm{~h}^{-1}\right)$ for any vessel entering the management area and continued use of recommended routes.

Vessel data. Data on vessel type, speed, and location were collected using the Automatic Identification System (AIS), which is a shipboard radio transponder operating in the VHF maritime radio frequencies for identifying and monitoring maritime traffic. As of December 31, 2004, International Maritime Organization (IMO) regulations require AIS on all vessels $>300$ gross tons on an international voyage and all tanker and passenger vessels regardless of size (IALA 2004). In the USA, AIS is required on all commercial vessels $>65 \mathrm{ft}(>20 \mathrm{~m})$ in length on an international voyage other than fishing or passenger vessels $<150$ gross tons (USCG 2003). AIS transponders send 2 different signals. One broadcasts every 2 to $10 \mathrm{~s}$ and includes the vessel's Maritime Mobile Service Identity (MMSI) number, navigational status (i.e. underway using engine, at anchor), rate of turn in degrees per minute, speed over ground in knots, latitude, longitude, course over ground, true heading, and time/date stamp. The second message broadcasts every $6 \mathrm{~min}$ and includes MMSI number, IMO number, radio call sign, name of vessel, type of vessel, dimensions of ship, draught of ship, destination, and estimated time of arrival. Static information is entered manually by the operator at the beginning of a voyage, while the dynamic data are primarily retrieved from the vessel's navigational instruments.

The aerial survey aircraft was equipped to collect AIS data from vessels operating in the area using a Sea Links Shine Micro Plus SL161 R dual channel AIS receiver. Data from the AIS receiver were downloaded to a laptop computer in the plane using ShipPlotter software (www.shipplotter.com), which continuously stored the data to a hard drive for the duration of the survey. Data were collected from ships at a maximum of $100 \mathrm{nmi}(185 \mathrm{~km})$ range only while the aircraft was airborne, thus the volume of vessel data was dependent upon survey time, which was governed, in part, by weather conditions and the number of whales encountered. The NEAq surveys were centered in the management area, which allowed for signals to be received well outside the management area (Fig. 1).

AIS data processing. The dynamic AIS data were imported into GIS format using the latitude and longitude for each location, and the static information for each vessel was joined to these data based upon the common MMSI attribute, and all data were projected into Universe Transverse Mercator, Zone 17, North American Datum 1983 coordinates.

During our surveys, the 3 major types of commercial vessels entering the SEUS calving ground from offshore and broadcasting AIS were cargo vessels, tankers, and tugs, and are used in the present study for comparative analyses. Using the vessel type attribute in the database, all of these 3 vessel types were selected if traveling at $>1 \mathrm{knot}$ speed $\left(>1.85 \mathrm{~km} \mathrm{~h}^{-1}\right)$ to eliminate vessels transmitting AIS signals while at anchor or in port. If a record did not have an entry for the type of vessel, vessel type was determined from the MMSI number in the Maritime mobile Access and Retrieval System (MARS) database (www.itu.int/cgibin/htsh/mars/ship_search.sh). A vessel was excluded if the vessel type information was not in the MARS system or the AIS static database.

Vessel speed analysis. To evaluate the compliance with either recommended (voluntary) or mandatory vessel speeds in the area, we analyzed the vessels that crossed the management boundary by converting the individual point locations to linear representations of each vessel track using a concatenated MMSI and date field; only those transits that crossed the management boundary were used in the analysis. Tugs were left out of the speed analysis because they primarily travel at speeds $<10$ knots ( $<18.5 \mathrm{~km} \mathrm{~h}^{-1}$; Hatch et al. 2008).

The response of vessels to the recommended and mandatory speed regulations in the SEUS right whale calving ground was measured using the change in the average speed of a vessel from the offshore side of the management area to the inshore side. The change in vessel speed entering the management area was determined by averaging the speed of each vessel in $10 \mathrm{nmi}(18.5 \mathrm{~km})$ wide zones (offshore and inshore of the management area boundary) to accommodate the time operators needed to slow the vessel down as they entered the area and not be affected by vessels slowing to pick up harbor pilots at entrance buoys (Fig. 1). The average speed was calculated in each zone (offshore and inshore) for each vessel, and the difference between these 2 average speeds was used to determine the change in the vessel speed entering the man- 
agement boundary. Each vessel had to have at least 3 positions in the offshore and 3 positions in the inshore buffer zones to be included in the analysis. In Year 4, only vessel data collected from December 9 or later were considered, because that is when the mandatory speed legislation was implemented.

We used 2 separate 2-way full-factorial ANOVAs to analyze differences in the change of vessel speed and the average speed inside the management boundary between vessels types and across years under different management measures. The change in speed variable was transformed using a Johnson $\mathrm{S}_{\mathrm{U}}$ transformation (Johnson 1955) to comply with the normality assumption of an ANOVA. The average speed inside the management boundary dependant variable was normally distributed. Significant main effects were analyzed using Tukey's honestly significant difference (HSD) post hoc test for multiple comparisons to evaluate which factors were statistically different (Zar 1996).

Some vessels return to the same port more than once per year and were recorded in the database multiple times in each year. To avoid violating the assumption of independence for an ANOVA and pseudo-replication, subsequent trips from a vessel in a given year were deleted from the data set. Consequently, there is only 1 record per unique vessel in any given year, but repeat vessels were examined across years to allow for each vessel to respond to new measures.

In addition to measuring the magnitude of vessel speed change after the vessels entered the management area, we assessed the rate of compliance to the recommended and mandatory speed regulations by summarizing the number of vessels that slowed to the recommended 12 knots $\left(22.2 \mathrm{~km} \mathrm{~h}^{-1}\right)$ in Year 1, the recommended 10 knots $\left(18.5 \mathrm{~km} \mathrm{~h}^{-1}\right)$ in Years 2 and 3, and the mandatory 10 knots $\left(18.5 \mathrm{~km} \mathrm{~h}^{-1}\right)$ in Year 4. Since the speed regulations are not defined as a fraction of a knot, a vessel was considered compliant to the recommended and mandatory rules if they slowed to within $1 \mathrm{knot}\left(1.85 \mathrm{~km} \mathrm{~h}^{-1}\right)$ of the speed regulation. For example, a vessel traveling at a speed of 10.9 knots $\left(20.2 \mathrm{~km} \mathrm{~h}^{-1}\right)$ inside the management area was categorized as compliant to the $10 \mathrm{knot}\left(18.5 \mathrm{~km} \mathrm{~h}^{-1}\right)$ speed requirement.

Recommended route analysis. The recommended vessel routes were established on November 15, 2006, which allows for a control year (Year 1) prior to routing measures and 3 evaluation years (Years 2, 3, and 4). The vessel transits (including tugs) created for the speed analysis were used to assess compliance with the recommended routes and compare these to the control year. However, if the distance between 2 AIS signals was $>5 \mathrm{nmi}(>9.3 \mathrm{~km})$ due to technical issues or gaps in survey effort, these sections of the vessel's transit were deleted from this analysis. The vessel tracks were clipped to a modified management boundary (Fig. 2) that eliminated areas inshore of the recommended routes, such as precautionary areas and shallow water areas. Precautionary areas are routing measures where vessels must navigate with caution (Allen 2005), and in the southeast management area they are centered on a near-shore sea buoy where harbor pilots board incoming vessels. Compliance was measured as the proportion of kilometers traveled within the recommended routes to the total kilometers traveled within the modified management boundary. Change in compliance was measured by comparing the difference in these proportions between the control year and the evaluation years.

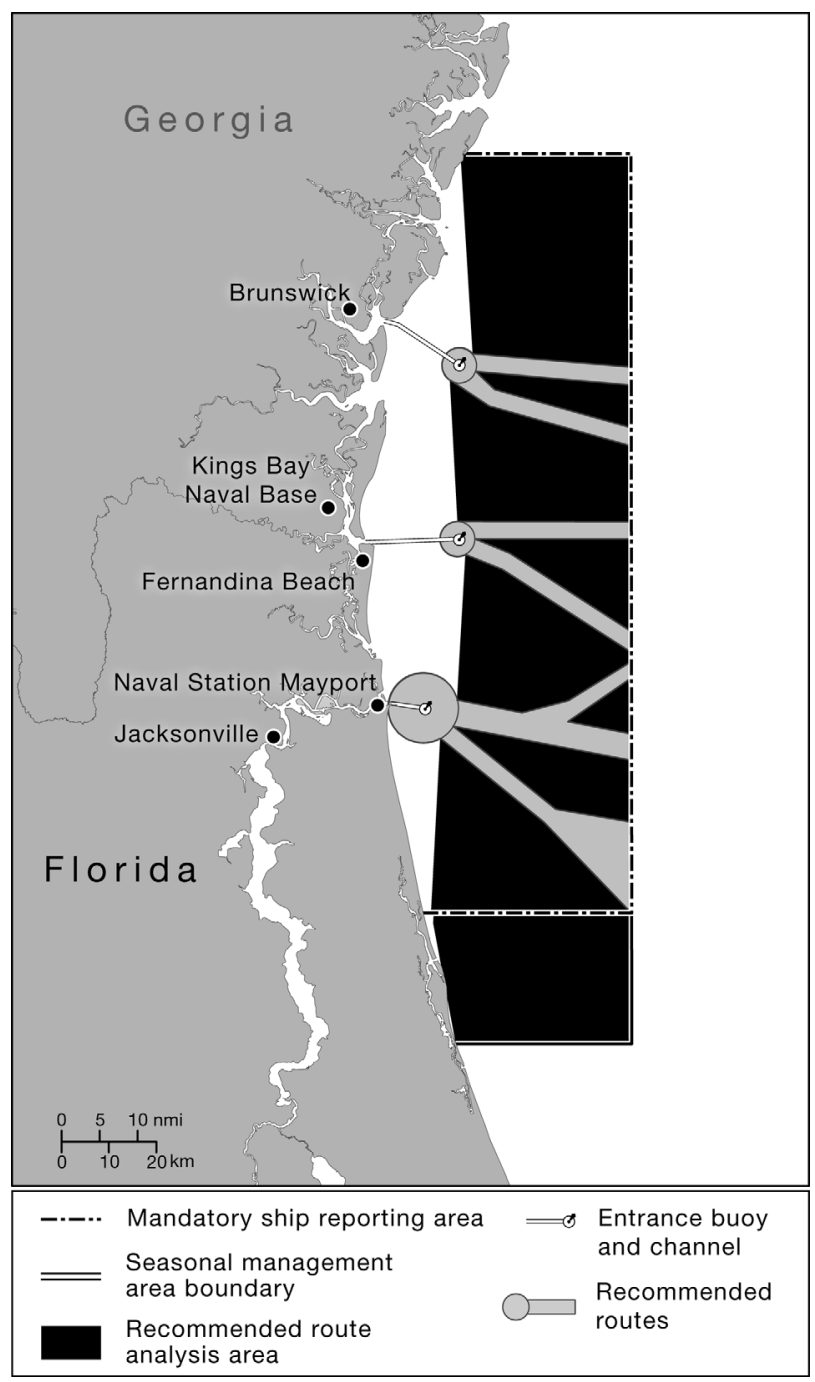

Fig. 2. Study area boundary for recommended-route analysis. The area was created by connecting the northern- and southern-most points of the recommended routes, not including the precautionary areas (gray circles). Eliminating areas that are not used by vessels because of existing river channels allowed for a more direct comparison of the compliance of vessel operators to recommended routes 


\section{RESULTS}

\section{Aerial surveys}

The NEAq aerial-survey team flew with an AIS receiver for 320, 387, 398, and 391 survey hours in Years $1,2,3$, and 4 , respectively; the average $( \pm \mathrm{SD})$ daily survey duration was $5.48 \pm 1.28 \mathrm{~h}$ (range: 0.4 to $8.8 \mathrm{~h}$ ) for all 4 yr. During these annual surveys, 964, 1013, 1593, and 1114 unique vessel trips were tracked by the AIS receiver, of which 140, 114, 84, and 83 met appropriate criteria and were selected in Years 1, 2, 3, and 4, respectively. Cargo vessels dominated other vessels in the survey area, making up $75 \%$ (331/421) of the total vessels analyzed over the $4 \mathrm{yr}$ of the present study.

\section{Vessel operator response to recommended/ mandatory speeds}

There were $82,82,59$, and 56 cargo vessels and tankers analyzed for vessel operator response to speed regulations in Years 1, 2, 3, and 4, respectively. There was a significant difference in the change in average speed of vessels from outside to inside the management area across years $(F=6.5443, \mathrm{p}<0.001)$ and by vessel type $(F=4.6069, \mathrm{p}=0.032)$. Vessels slowed significantly more in Year 4 (Tukey HSD with $\alpha=0.05, q=2.585$ ) and with more variation than other years as they entered the management area (Fig. 3). In Year 4, the average decrease in vessel speed as they entered the management boundary was 3.0 knots $\left(5.6 \mathrm{~km} \mathrm{~h}^{-1}\right)$, compared to 0.0 knots, 0.3 knots $\left(0.5 \mathrm{~km} \mathrm{~h}^{-1}\right)$, and 0.8 knots $(1.5 \mathrm{~km}$ $\mathrm{h}^{-1}$ ) in Years 1, 2, and 3, respectively. Cargo vessels slowed their speed more than tankers, but only with modest significance $(p=0.038)$, with an average decrease of 1 knot $\left(1.85 \mathrm{~km} \mathrm{~h}^{-1}\right)$ compared to tankers' decrease of $0.14 \mathrm{knot}\left(0.26 \mathrm{~km} \mathrm{~h}^{-1}\right)$ over the $4 \mathrm{yr}$.

There was a significant difference in the average speed of vessels inside the management area over the years $(F=13.451, \mathrm{p}<0.001)$, with vessels in Year 4 under mandatory speed legislation traveling significantly slower (Tukey HSD with $\alpha=0.05, q=2.585$ ) at 10.5 knots $\left(19.6 \mathrm{~km} \mathrm{~h}^{-1}\right)$ compared to an average 14.5 knots $\left(26.9 \mathrm{~km} \mathrm{~h}^{-1}\right)$ under voluntary recommended speeds in Years 1 to 3 (Table 1).

Overall vessel compliance to voluntary recommended speeds remained low in the first 3 seasons: 23.2, 9.8, and $13.6 \%$ for Years 1, 2, and 3, respectively. However, during Year 4, when mandatory speeds were implemented, 42 out of 56 vessels $(75.0 \%)$ complied with the speed legislation, with $48.0 \%$ of those vessels actively slowing to the mandatory speed compared to an average of $6.4 \%$ of the vessels actively slowing in all other years (Table 2).

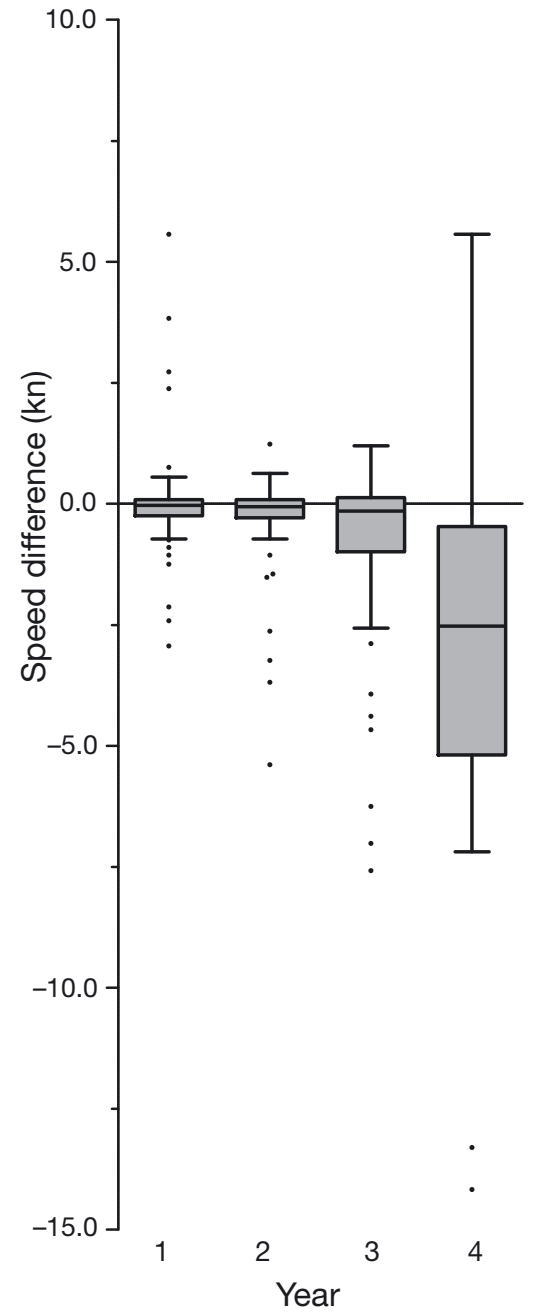

Fig. 3. Change in vessel speed across the years. Negative speed change indicates slowing inside the right whale management area; positive speed change indicates increasing speed when entering the management area. Change in speed was calculated for each vessel by averaging the speed of a vessel track inshore of the management boundary subtracted from the average offshore speed calculated in $10 \mathrm{nmi}$ $(18.52 \mathrm{~km})$ zones. Year 4 is significantly different from all other years. Each box shows the median (line in middle) and is bounded by the lower and upper quartiles. The whiskers represent data 1.5 times the interquartile range or the minimum and maximum values, whichever is smaller. The small dots are extreme values outside 1.5 times the interquartile range

\section{Recommended routes}

There was an overall increase in use of the recommended routes over the years from $42.6 \%$ in the control year (Year 1) to $96.2 \%$ by Year 4 , with the biggest increase in the second year of implementation. There was a $9.1 \%$ increase in use from the control year (Year 1: $42.6 \%$ ) to the first year recommended routes were placed on the nautical charts (Year 2: $51.7 \%$ ). However, 
Table 1. Vessel speed (knots, mean \pm SD) by vessel type within the inshore and offshore $10 \mathrm{nmi}(18.5 \mathrm{~km})$ areas of the management boundary for each year (Year 1: 2005-06; Year 4: 2008-09)

\begin{tabular}{|lllllr|}
\hline \multirow{2}{*}{ Year } & \multicolumn{2}{c}{ Cargo vessels } & & \multicolumn{2}{c|}{ Tankers } \\
\cline { 2 - 5 } & Offshore & Inshore & & Offshore & Inshore \\
\hline 1 & $14.6 \pm 2.4$ & $14.6 \pm 2.3$ & $13.8 \pm 1.6$ & $13.8 \pm 1.6$ \\
2 & $15.1 \pm 3.0$ & $14.8 \pm 3.2$ & $13.7 \pm 1.3$ & $13.7 \pm 1.3$ \\
3 & $16.0 \pm 2.6$ & $15.0 \pm 3.5$ & $13.8 \pm 2.0$ & $13.4 \pm 1.6$ \\
4 & $13.9 \pm 3.9$ & $10.5 \pm 2.5$ & $11.7 \pm 1.5$ & $10.8 \pm 1.5$ \\
\hline
\end{tabular}

Table 2. Vessels complying with the recommended (R) and mandatory (M) speed restrictions each year (Year 1: 2005-06; Year 4: 2008-09)

\begin{tabular}{|c|c|c|c|c|c|}
\hline \multirow{2}{*}{ Year } & \multirow{2}{*}{$\begin{array}{l}\text { Speed } \\
\text { restriction }\end{array}$} & \multirow{2}{*}{$\begin{array}{l}\text { Total no. } \\
\text { of vessels } \\
\text { analyzed }\end{array}$} & \multirow[b]{2}{*}{$\begin{array}{l}\text { Slowing to } \\
\mathrm{R} \text { or } \mathrm{M} \text { speed }\end{array}$} & \multirow{2}{*}{$\begin{array}{c}\text { No. (\%) of vessels } \\
\text { Continuing at } \\
\text { R or M speed }\end{array}$} & \multirow{2}{*}{$\begin{array}{l}\text { Total in } \\
\text { compliance }\end{array}$} \\
\hline & & & & & \\
\hline 1 & $\mathrm{R}$ & 82 & $4(4.9)$ & 15 (18.3) & $19(23.2)$ \\
\hline 2 & $\mathrm{R}$ & 82 & $2(2.4)$ & $6(7.3)$ & $8(9.8)$ \\
\hline 3 & $\mathrm{R}$ & 59 & 7 (11.9) & $1(1.7)$ & 8 (13.6) \\
\hline 4 & M & 56 & $27(48.2)$ & $15(27.8)$ & $42(75)$ \\
\hline
\end{tabular}

the second year of implementation (Year 3: $84.0 \%$ ) saw an overall increase of $41.4 \%$ from the control season, while the third year (Year 4) of implementation increased an additional $12.2 \%$ to $96.2 \%$ of use (Fig. 4).

\section{DISCUSSION}

Since the inception of the North Atlantic right whale recovery plan in 1991, ship collisions have been identified as the most significant threat to the right whale population and the leading cause of mortality (NOAA 2004, Kraus et al. 2005). To reduce vessel strikes, it is necessary either to reduce the probability of a vesseland-whale encounter, reduce the impact of a vessel strike by slowing vessels down, or a combination of the two (Vanderlaan et al. 2008). NOAA has implemented many actions since the 1990s to help protect right whales from vessel collisions, including daily aerial surveys of right whales and mariner notifications, the MSR system, and educating mariners through publications and training. After the educational efforts and surveys failed to eliminate vessel strikes, NOAA implemented recommended routes and mandatory speed restrictions to reduce both the probability of an encounter and the lethality of the impact if a strike did occur.

When AIS became available as a tool to monitor vessel traffic, NEAq recognized that using an aerial survey platform to collect this information could significantly expand and improve information on vessels using this important right whale habitat. However, there are limitations to using AIS data collected this way. By using aerial surveys to collect the data, we collect no data during poor weather or at night. Also, AIS data alone cannot assess the total risk of all vessels to right whales, because military and smaller vessels are not required to broadcast AIS, and are exempt from the mandatory speed rule. Military traffic may represent a significant portion of the vessels traveling in the study area because of the 2 naval bases in the southeast. Yet, AIS does collect information about each individual vessel and speed, and this technology has just recently begun to be used by the National Marine Fisheries Service (NMFS) and the US Coast Guard to enforce this mandatory legislation. Enforcement has been found to increase compliance to speed regulation within manatee habitats (Gorzelany 2004, Laist \& Shaw 2006).

Compliance with recommended voluntary routes increased significantly over the present study, reaching a $96.2 \%$ level by the third year of implementation. The large increase in compliance between Years $2(51.7 \%)$ and $3(84.0 \%)$ of implementation could have been due to enhanced educational efforts regarding these routing measures, and the timing of mariners updating their nautical charts. Right whales still travel through the entire management area, and an average of $18 \%$ of the NEAq field-based sightings occurred within the recommended routes during the surveys since implementation. However, alternative routing scenarios relative to right whale occurence probabilities were analyzed by Fonnesbeck et al. (2008), who found that the option that most closely resembles the current recommended routes reduces the potential encounter rate by $44 \%$ compared to no routing.

A total of $75 \%$ of vessel operators carrying AIS complied with the mandatory speed restrictions compared with $15 \%$ compliance with recommended speed restrictions. The lack of compliance to recommended voluntary speed restrictions is in stark contrast to the compliance to recommended voluntary routes. The discrepancy between these 2 voluntary measures could be due to how the information was received or how much the regulation affects vessel operations. Course corrections can have limited effect on overall vessel transit time, while slowing of vessels can substantially increase transit time (Vanderlaan et al. 2008). Voluntary routing measures were placed on nautical charts, while recommended speeds were communicated through the MSR system and nautical publica- 


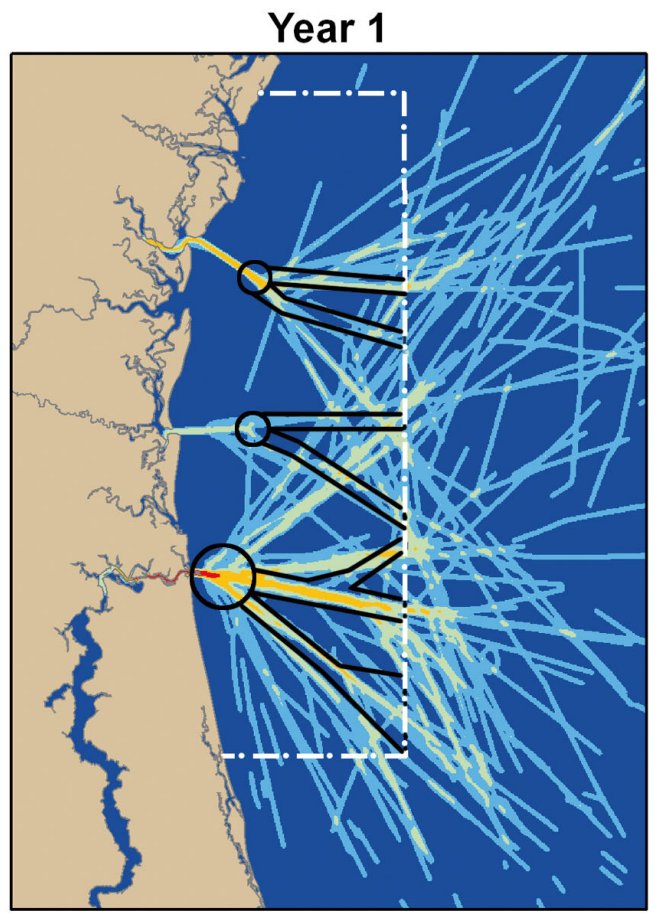

Year 3

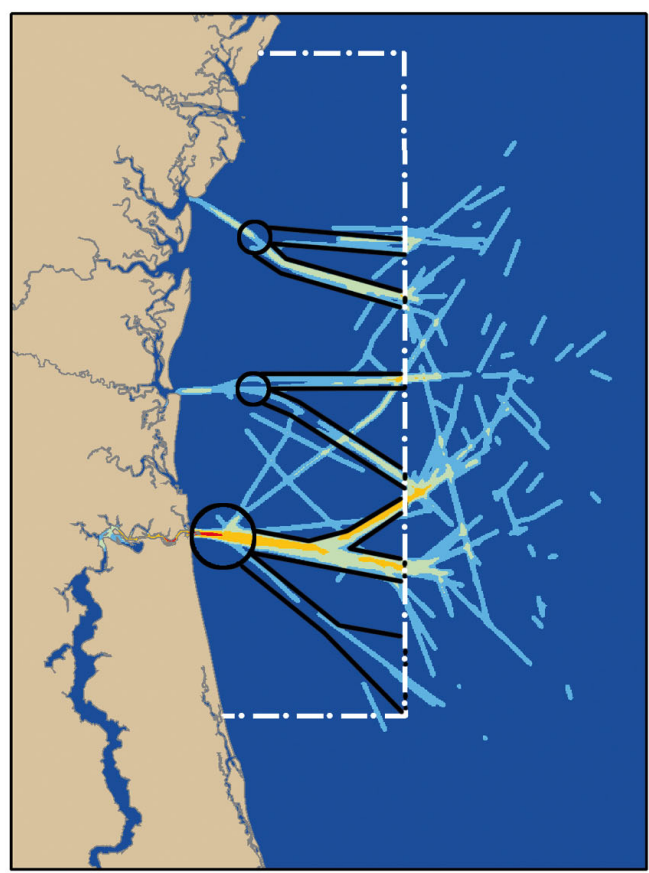

Density of AIS tracks

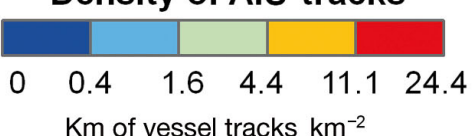

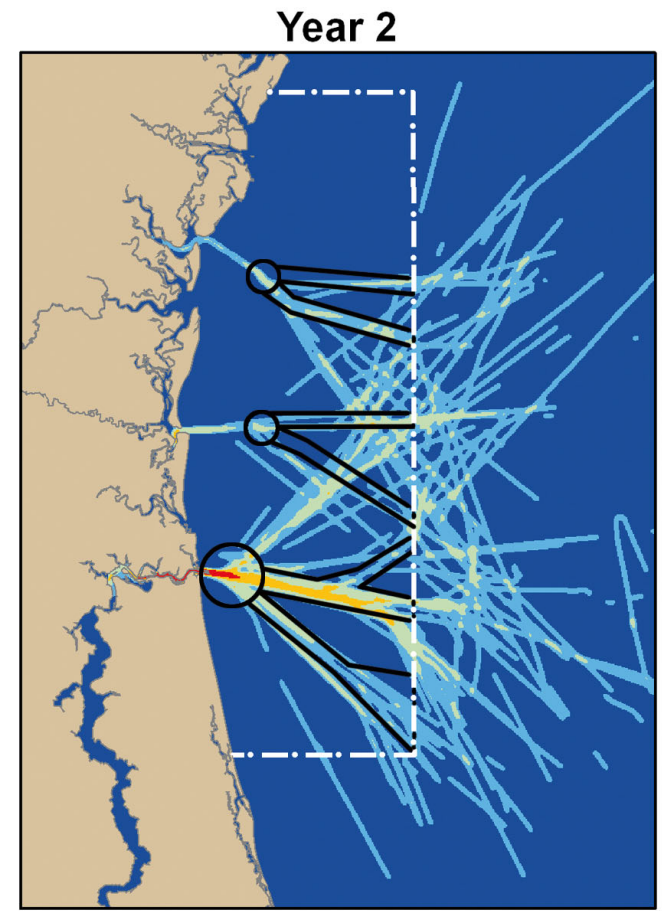

Year 4

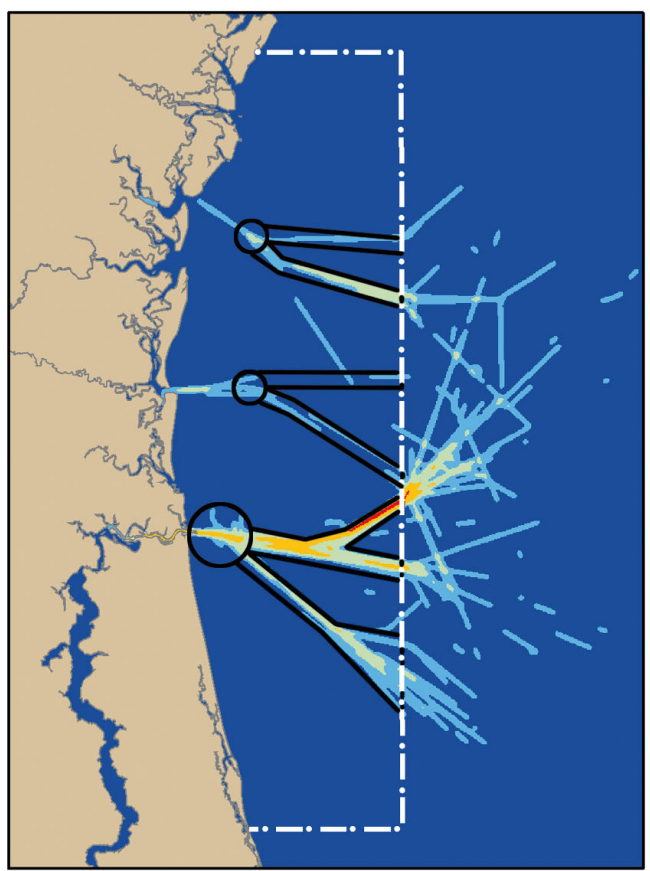

$0 \quad 1530 \mathrm{~km}$

Fig. 4. Vessel traffic density relative to the recommended routes and management boundaries (dash-dotted line) before (Year 1) and after (Years 2 to 4 ) the recommended routes were established. The percentage of use inside the recommended lanes increased from a baseline of $43 \%$ (1886 km inside/4427 km total) before implementation to $52 \%(1661 \mathrm{~km}$ inside/3212 $\mathrm{km}$ total) in Year 2, $84 \%$ (1548 km inside/1842 km total) in Year 3, and $96 \%$ (1692 km inside/1759 km total) in the final year of the study and when the seasonal management area was implemented extending the management area $15 \mathrm{nmi}(27.8 \mathrm{~km})$ to the south. AIS: Automatic Identification System 
tions. Vessel operators could be accustomed to following lanes on nautical charts and so complied with these measures without assessing whether the lanes were voluntary or mandatory.

From 1989 to 2008, there were 6 confirmed right whale ship-strike mortalities in the SEUS, a rate of 0.32 mortalities $\mathrm{yr}^{-1}$ or approximately 1 mortality detected every 3 yr. Using the baseline probability of a vessel and whale encounter in the SEUS (0.57) from Vanderlaan et al. (2009), we can calculate the total effect that speed restrictions, compliance rates, and routing had on the right whale mortality rates. The relative risk reduction from recommended routing was a function of compliance $(96.2 \%)$ and the decrease in the likelihood of a vessel and whale encounter $(44 \%$; Fonnesbeck et al. 2008) times the baseline probability of an encounter (0.57). The relative risk reduction from the recommended routes alone was $54.3 \%$.

Applying the Vanderlaan \& Taggart (2007) model to the average speed of vessels inside the management area prior to the mandatory rule indicates a 0.74 probability that a vessel collision would be lethal; after the mandatory speed rule, the probability dropped to 0.36 . The relative risk reduction from mandatory speed restrictions was a function of the reduction in the probability of a lethal event accounting for the compliance rates during the final year of the study $(0.46)$ times the baseline probability of an encounter, reducing the relative risk by $38.5 \%$. By combining both the recommended routing and mandatory speeds the relative risk was reduced by $71.9 \%$.

Applying these reductions of relative risk to the annual mortality rate, ship routing reduces the annual mortality rate to 0.15 , or approximately 1 whale every 6.6 yr. The mandatory speed restrictions alone reduce the annual mortality rate to 0.20 or approximately 1 whale every 5 yr. The combined effect of both recommended routes and mandatory speed reduced the annual mortality rate to 0.09 or approximately 1 whale every $11 \mathrm{yr}$.

This assessment underestimates total mortality because of low carcass-detection rates, and offshore carcasses are infrequently necropsied to identify the cause of death (Kraus et al. 2005, Moore et al. 2007, Glass et al. 2009). Nevertheless, the current regulations in place are reducing the known right whale mortality from ships in the calving ground by more than half, a significant step toward reducing mortality by 2 whales $\mathrm{yr}^{-1}$, the level needed to see population increases (Fujiwara \& Caswell 2001).

The effectiveness of the speed-restriction legislation will be reviewed in advance of 2013 to determine if the regulation should be extended beyond the 5 yr timeframe it presently mandates. With right whale population growth hovering around the replacement rate
$(1.8 \%$; NOAA 2009$)$ and the juxtaposition of the only known calving ground with major shipping ports in the SEUS, these results support long-term implementation of both speed reduction and restricted routes for the survival and recovery of the North Atlantic right whale.

Acknowledgements. This work was made possible by funding from the US Army Corps of Engineers (South Atlantic Division), US Navy, US Coast Guard, and US NOAA National Marine Fisheries Service. We are grateful to the observers of the New England Aquarium southeast aerial observer team: J. Cunha, J. Hampp, B. Kraus, K. Mahoney-Robinson, M. Montgomery, G. Munoz, H. Nicotri, P. Nilsson, and Z. Swaim; and the pilots of Orion Aviation and Eagle Cap Aviation: B. Foster, H. Friedman, N. Jorgenson, M. Mayer, K. Pierson, S. Ridlon, R. Salmon, and M. Vigus, who collected the AIS data for this study. We thank P. Hamilton, D. Wiley, and 1 anonymous reviewer for reviewing and improving this manuscript, and $\mathrm{M}$. Tlusty for his help with the statistical analysis.

\section{LITERATURE CITED}

Allen CH (2005) Farwell's rules of the nautical road. Naval Institute Press, Annapolis, MD

Fonnesbeck CJ, Garrison LP, Ward-Geiger LI, Baumstark RD (2008) Bayesian hierarchichal model for evaluating the risk of vessel strikes on North Atlantic right whales in the SE United States. Endang Species Res 6:87-94

Fujiwara M, Caswell H (2001) Demography of the endangered North Atlantic right whale. Nature 414:537-541

Glass AH, Cole TVN, Garron M (2009) Mortality and serious injury determinations for baleen whale stocks along the United States eastern seaboard and adjacent Canadian Maritimes, 2003-2007. Northeast Fish Sci Cent Ref Doc 09-04. Northeast Fisheries Science Center, NOAA, Woods Hole, MA

Gorzelany JF (2004) Evaluation of boater compliance with manatee speed zones along the Gulf Coast of Florida. Coast Manage 32:215-226

Hatch L, Clark C, Merrick R, Van Parijs S and others (2008) Characterizing the relative contributions of large vessels to total ocean noise fields: a case study using the Gerry E. Studds Stellwagen Bank National Marine Sanctuary. Environ Manage 42:735-752

IALA (International Association of Marine Aids to Navigation and Lighthouse Authorities) (2004) IALA guideline no. 1028 on the Automatic Identification System (AIS): Part I. Operational issues. IALA, Saint Germain en Laye, France. www.navcen.uscg.gov/pdf/AIS/IALA_AIS_Guidelines_ Vol1_Pt1 \%20OPS\%20(1.3).pdf

Johnson NL (1955) Systems of frequency curves derived from the first law of Laplace. Trab Estadistica 5:283-291

Knowlton AR, Kraus SD (2001) Mortality and serious injury of northern right whales (Eubalaena glacialis) in the western North Atlantic Ocean. J Cetacean Res Manag 2(Spec Issue):193-208

- Kraus SD (1990) Rates and potential causes of mortality in North Atlantic right whales (Eubalaena glacialis). Mar Mamm Sci 6:278-291

Kraus SD, Rolland RM (2007) Right whales in the urban ocean. In: Kraus SD, Rolland RM (eds) The urban whale: North Atlantic right whales at the crossroads. Harvard University Press, Cambridge, MA, p 1-38 
Kraus SD, Prescott JH, Knowlton AR, Stone GS (1986) Migration and calving of right whales (Eubalaena glacialis) in the western North Atlantic. Rep Int Whal Comm 10(Spec Issue):139-144

Kraus SD, Brown MW, Caswell H, Clark CW and others (2005) North Atlantic right whales in crisis. Science 309: 561-562

Laist DW, Shaw C (2006) Preliminary evidence that boat speed restrictions reduce deaths of Florida manatees. Mar Mamm Sci 22:472-479

Laist DW, Knowlton AR, Mead JD, Collet AS, Podesta M (2001) Collisions between ships and whales. Mar Mamm Sci 17:35-75

Moore MJ, McLellan WA, Daoust PY, Bonde RK, Knowlton AR (2007) Right whale mortality: a message from the dead to the living. In: Kraus SD, Rolland RM (eds) The urban whale: North Atlantic right whales at the cross-roads. Harvard University Press, Cambridge, MA, p 358-379

NOAA (National Oceanic and Atmospheric Administration) (2004) Advance notice of proposed rulemaking (ANPR) on right whale ship strike strategy. Fed Regist 69:3085730864

NOAA (National Oceanic and Atmospheric Administration) (2006) Proposed rule to implement speed restrictions to reduce the threat of ship collisions with North Atlantic right whales. Fed Regist 71:36299-36319

NOAA (National Oceanic and Atmospheric Administration) (2008) Final rule to implement speed restrictions to reduce the threat of ship collisions with North Atlantic right

Editorial responsibility: Clive McMahon,

Darwin, Australia whales. Fed Regist 73:60173-60191

NOAA (National Oceanic and Atmospheric Administration) (2009) North Atlantic right whale (Eubalaena glacialis): western Atlantic stock. Stock assessment report. Office of Protected Resources, NOAA, Silver Spring, MD. www. nmfs.noaa.gov/pr/pdfs/sars/ao2009whnr-w.pdf

USCG (United States Coast Guard) (2003) Automatic Identification System vessel carriage requirement. Fed Regist 68:60559-60570

USCG (United States Coast Guard) (2006) Port access route study to analyze potential vessel routing measures for reducing vessel (ship) strikes of North Atlantic right whales. Fed Regist 71:29876-29878

Vanderlaan ASM, Taggart CT (2007) Vessel collisions with whales: the probability of lethal injury based on vessel speed. Mar Mamm Sci 23:144-156

Vanderlaan ASM, Taggart CT, Serdynska AR, Kenney RD, Brown MW (2008) Reducing the risk of lethal encounters: vessels and right whales in the Bay of Fundy and on the Scotian Shelf. Endang Species Res 4:283-297

Vanderlaan ASM, Corbett JJ, Green SL, Callahan JA and others (2009) Probability and mitigation of vessel encounters with North Atlantic right whales. Endang Species Res 6:273-285

> Ward-Geiger LI, Silber GK, Baumstark RD, Pulfer TL (2005) Characterization of ship traffic in right whale critical habitat. Coast Manag 33:263-278

Zar JH (1996) Biostatistical analysis, 3rd edn. Prentice-Hall, Upper Saddle River, NJ

Submitted: May 18, 2010; Accepted: January 4, 2011

Proofs received from author(s): April 22, 2011 